Check for updates

Cite this: Mater. Adv., 2021,

2, 1313

Received 23rd September 2020,

Accepted 8th January 2021

DOI: $10.1039 / \mathrm{d} 0 \mathrm{ma} 00729 \mathrm{c}$

rsc.li/materials-advances

\section{Caffeine vehiculation into alpha-zirconium phosphate: a multifunctional intercalation product and its application for modified topical release}

\author{
M. Bastianini, (D)* M. Sisani, A. Petracci, I. Di Guida, C. Faffa and F. Cardellini
}

Caffeine possesses many important biological effects and is known to be a model drug for topical applications. Zirconium phosphate (ZrP) is able to intercalate basic molecules and it is an effective drug carrier. The vehiculation of drugs in lamellar solids can finely tune their properties: in this article the first intercalation of caffeine in ZrP is reported. The intercalation strategy was designed on the basis of the chemical properties of the host and guest, and the synthesized product was fully chemically-physically characterized and tested for topical release using the Franz cell diffusion system.

\section{Introduction}

Caffeine (1,3,7-trimethylxanthine, Fig. 1) has been a part of our global history for thousands of years; each country has its own story and source of caffeine: there are 63 different species of plants known to contain caffeine. ${ }^{1}$

Caffeine was first extracted from cocoa beans into its purest form, a white powder, in the 1820 s by a German Scientist named Friedrich Ferdinand Runge.

It is a weak base belonging to the methylxanthine class, and it acts as a central nervous system stimulant. The biological effects of caffeine are mainly due to its ability to reversibly block the action of adenosine on its receptors. ${ }^{2}$

Caffeine (CAF) has many interesting activities, because it can treat and prevent bronchopulmonary dysplasia in premature infants; ${ }^{3}$ it may confer a modest protective effect against some diseases, ${ }^{4}$ including Parkinson's disease,${ }^{5}$ and it can improve the effect of anticancer drugs like 5-fluorouracil and cisplatinum. ${ }^{6}$ Recently Li et al. $^{7}$ demonstrated that caffeine has an important activity in protecting skin from oxidative stressinduced senescence through the activation of autophagy. In topical application caffeine is used as an active ingredient in anti-cellulite products. CAF stimulates the degradation of fats during lipolysis through the inhibition of the phosphodiesterase activity preventing excessive accumulation of fat in cells. It also increases the microcirculation of blood in the skin. ${ }^{8}$ Moreover topical application of caffeine to mouse skin after UV irradiation promotes the deletion of DNA-damaged keratinocytes and may partially diminish photodamage as well as photocarcinogenesis. $^{9}$

$R \& D$ Department, Prolabin \& Tefarm S.r.l., Via dell'Acciaio 9, 06134 Perugia, Italy.E-mail: maria.bastianini@prolabintefarm.com
Caffeine is also recommended by the OECD as test substance for topical applications because it has been widely tested. As a hydrophilic drug, it possesses a $\log P$ of -0.07 that corresponds to a slow permeation in topical applications. Moreover it forms aggregates in aqueous solutions. ${ }^{10}$ Due to its high crystallization tendency, in formulation with concentration higher than $1 \%$ caffeine needs to be pre-solubilized in alcohol or an alcohol-water mixture. ${ }^{11}$

Zirconium phosphate of alpha type is an acidic, inorganic cation exchange material which has a layered structure with formula $\mathrm{Zr}\left(\mathrm{HPO}_{4}\right)_{2} \cdot \mathrm{H}_{2} \mathrm{O} .{ }^{12,13}$ Zirconium phosphate can be easily functionalized through intercalation reactions with bases. ${ }^{14}$ This solid has been widely studied in academic literature with the aim of vehiculating bioactive organic molecules, as a drug carrier for cancer therapy, ${ }^{15-18}$ anti-inflammatory drugs $^{19}$ and also antibiotics. ${ }^{20} \mathrm{ZrP}$ is composed of stacking layers made of planes of $\mathrm{Zr}$ atoms bonded, on both sides, to monohydrogen phosphate groups. Each phosphate group is bonded to three $\mathrm{Zr}$ atoms of the plane, while each zirconium is

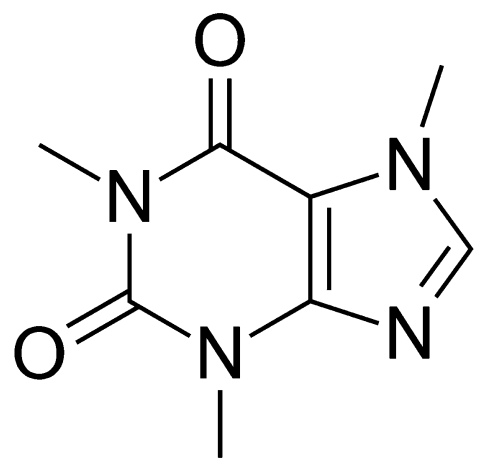

Fig. 1 Chemical structure of caffeine. 
octahedrally coordinated by six oxygens of six different monohydrogen phosphate groups. The water molecules are located in the zeolitic cavities of the interlayer region. ${ }^{21}$

In the past, several authors have reported that caffeine can be successfully intercalated in lamellar solids reaching interesting goals. $^{22-28}$ Herein we report the first intercalation of CAF on ZrP, obtaining an intercalation product that has been successfully used to prepare a stable emulsion. The cream has been tested for a topical application by the OEDC method. ${ }^{29}$ The results demonstrate that the new intercalation compound opens new frontiers in the development of high-tech products for topical application.

\section{Materials and methods}

\section{Chemicals and solvents}

Propylamine, monobasic potassium phosphate $\left(\mathrm{KH}_{2} \mathrm{PO}_{4}\right)$ and dibasic sodium phosphate heptahydrate $\left(\mathrm{Na}_{2} \mathrm{HPO}_{4} \cdot 7 \mathrm{H}_{2} \mathrm{O}\right)$ were purchased from Sigma-Aldrich. Zirconyl chloride octahydrate was supplied by MEL Chemicals and 75\% phosphoric acid was purchased from C.M. Chimica. Anhydrous caffeine, xanthan gum, cetearyl alcohol, paraffin oil, petrolatum, steareth-2, ceteareth-20, glyceryl stearate, and sodium chloride were supplied by ACEF. Strat-M membranes were provided by Merck. Solvents and materials were of reagent grade and used without further purification.

\section{ZrP synthesis}

Crystalline zirconium phosphate $\mathrm{Zr}\left(\mathrm{HPO}_{4}\right)_{2} \cdot \mathrm{H}_{2} \mathrm{O}$ of alpha type was obtained by refluxing zirconyl chloride $\left(\mathrm{ZrOCl}_{2} \cdot 8 \mathrm{H}_{2} \mathrm{O}\right)$ in a $10 \mathrm{M}$ phosphoric acid solution for $48 \mathrm{~h} .{ }^{12}$ The residual solid was centrifuged, washed 3 times with water and dried in an oven at $60{ }^{\circ} \mathrm{C}$. The dried solid was properly dissolved and ICPOES elemental analysis, combined with thermogravimetric analysis, allowed the determination of the following chemical formula: $\mathrm{Zr}\left(\mathrm{HPO}_{4}\right)_{2} \cdot \mathrm{H}_{2} \mathrm{O}$.

\section{Intercalation of CAF in $\mathrm{ZrP}$}

A colloidal dispersion of exfoliated zirconium phosphate was prepared by titrating dropwise $5 \mathrm{~g}$ of solid $\mathrm{ZrP}$ suspended in $330 \mathrm{~mL}$ of water with $165 \mathrm{~mL}$ of $0.1 \mathrm{M}$ propylamine solution at room temperature and under vigorous stirring. Then, a solution of $\mathrm{HCl}$ was added to the colloidal dispersion until complete exchange of the propylammonium ions with protons, regenerating the acid form of $\alpha$-ZrP in a gel dispersion. In a second step, a solution containing $6.4 \mathrm{~g}$ of CAF in $250 \mathrm{~mL}$ of water was added to the gel and the mixture was stirred for $24 \mathrm{~h}$ at room temperature. The reaction mixture was centrifuged, washed twice with deionized water and dried in an oven at $60{ }^{\circ} \mathrm{C}$. The white solid obtained (ZrP-CAF) was finely ground with a mortar.

\section{Extraction of CAF from ZrP-CAF}

$0.5 \mathrm{~g}$ of ZrP-CAF was suspended in $50 \mathrm{~mL}$ of $0.1 \mathrm{~N}$ aqueous solution of $\mathrm{NaCl}$. Then the mixture, kept under magnetic stirring, was slowly titrated with $0.1 \mathrm{~N} \mathrm{NaOH}$ until complete formation of $\mathrm{Na}_{2} \mathrm{Zr}\left(\mathrm{PO}_{4}\right)_{2} \cdot{ }^{30}$ The obtained dispersion was filtered and the solution was analyzed three times by UV-vis in order to determine caffeine content in the solid. The obtained value was $31.8 \pm 0.6 \mathrm{wt} \%$.

\section{Cream preparation}

A cream containing pure caffeine as a reference was prepared. $4 \%$ of caffeine was suspended in the following cream: xanthan gum $0.2 \%$, steareth- $21 \%$, ceteareth-20 $1.5 \%$, cetearyl alcohol $2 \%$, petrolatum $2 \%$, glyceryl stearate $5 \%$, paraffin oil $8 \%$, and water $76.3 \%$. In the second cream an amount of ZrP-CAF corresponding to $4 \%$ of caffeine was dispersed in steareth-2 $1 \%$, ceteareth-20 $1.5 \%$, cetearyl alcohol $2 \%$, petrolatum $2 \%$, glyceryl stearate $5 \%$, paraffin oil $8 \%$, and water $68.3 \%$.

\section{Analytical procedures and instrumentation}

6.1 Inductively coupled plasma-optical emission spectrometry. The $\mathrm{Zr}$ and $\mathrm{P}$ content in the synthesized $\mathrm{ZrP}$ was determined using an ICP-OES Varian 700-ES series, after dissolving the sample using few drops of HF and deionized water. The solution was analyzed after a proper dilution.

6.2 Thermal analysis. Thermogravimetric analysis (TGA) and differential scanning calorimetry (DSC) of the samples were carried out with an STD Q600 thermal analyzer TA Instrument, in air flow with a heating rate of $10{ }^{\circ} \mathrm{C} \mathrm{min}^{-1}$.

6.3 UV-Vis spectrophotometry. UV-VIS analysis was carried out using a UV-visible double-beam spectrophotometer (Jasco $\mathrm{V}-750)$. The CAF released in the permeation tests was detected by UV-vis spectrophotometry at the wavelength of maximum absorption of caffeine in the phosphate buffer $(\lambda=273 \mathrm{~nm})$. A suitable calibration was carried out by dissolving known amounts of caffeine in a suitable volume of phosphate buffer. Eight standards and a blank sample were then prepared and analyzed in order to obtain the calibration curve (Fig. 2). The correlation coefficient of the calibration $r$ was 0.99973 . Tests were carried out in triplicate and the results were reported as average values. Cuvettes of $0.1 \mathrm{~cm}$ path length were filled with

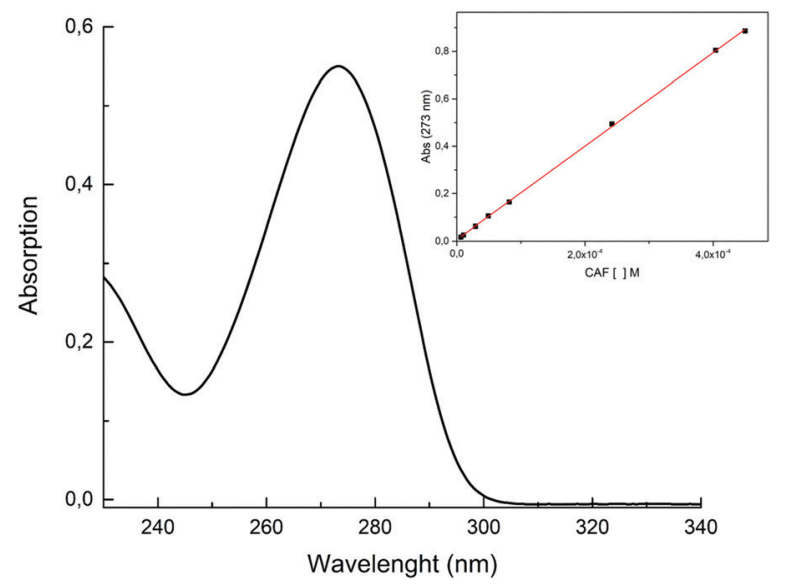

Fig. 2 Linear regression for the determination of caffeine in a phosphate buffer at $\mathrm{pH} 7.4$. 
the $0.4 \mathrm{~mL}$ samples and the concentration was measured using the buffer solution as blank.

6.4 FT-IR analysis. FT-IR spectra were recorded at room temperature using a FT-IR-4600 Jasco. Typically, each spectrum was obtained in the spectral region from 600 to $4000 \mathrm{~cm}^{-1}$. For data collection an ATR crystal in ZnSe has been used.

6.5 X-ray powder diffraction. The X-ray powder diffraction (XRPD) patterns were recorded with a Bruker D2 Phaser diffractometer operating at $30 \mathrm{kV}$ and $15 \mathrm{~mA}$, a step size of $0.022 \theta$ degrees and time per step of $1 \mathrm{~s}$, using the $\mathrm{Cu} \mathrm{K} \alpha$ radiation and a multistrip LYNXEYE SSD160 detector.

6.6 SEM analysis. The morphology of the samples was investigated with a FEG LEO 1525 scanning electron microscope (FE-SEM). FE-SEM micrographs were collected by depositing the samples on a stub holder and after a sputter coating with chromium for $20 \mathrm{~s}$.

6.7 Permeation studies. Permeation studies from the creams containing pure caffeine and ZrP-CAF were performed using a Franz Diffusion Cell (PermeGear, Inc., Bethlehem, P.A., $20 \mathrm{~mm}$ diameter), following the OECD guideline for measuring skin absorption and dermal delivery in vivo. ${ }^{29}$ Buffer solution at pH 7.4 was chosen as acceptor solution, and prepared as follows: 0.6 potassium dihydrogen phosphate, $6.4 \mathrm{~g}$ disodium hydrogen phosphate, $5.85 \mathrm{~g}$ sodium chloride, and deionized water to $1 \mathrm{~L}^{31}$ The system was equilibrated at $32{ }^{\circ} \mathrm{C}$ using an external circle bath. The solubility test of caffeine in the receptor fluid at $32{ }^{\circ} \mathrm{C}$ was carried out: the molecule was really soluble in the chosen fluid $\left(46 \mathrm{~g} \mathrm{~L}^{-1}\right)$. The amount of caffeine to be placed in the donor chamber was fixed at $8 \mathrm{mg}$ (equivalent to $200 \mathrm{mg}$ of cream), so that the fluid would not act as a barrier to absorption. The amount of cream was also calculated in order to be in the range indicated in the method for mimicking human exposure. The amount of caffeine applied in both cases was $2.5 \mathrm{mg} \mathrm{cm}^{-2}$. The Franz Cell is composed of a donor chamber and a receiver chamber with a volume of $15 \mathrm{~mL}$. The two parts were separated by a synthetic membrane simulating human skin: Strat-M membrane. ${ }^{32,33}$ That membrane is ready to use. On the donor chamber $200 \mathrm{mg}$ of cream were carefully spread on the membrane surface. The chambers were left unoccluded. Aliquots $(0.40 \mathrm{ml})$ of the acceptor fluid were collected at predetermined time intervals $(30,60,90,120$, $180,240,300$, and $360 \mathrm{~min}$ ) and immediately replaced by the same volume of fluid equilibrated at $32{ }^{\circ} \mathrm{C}$. Tests were carried out in triplicate; the results were reported as average values and the error was expressed as $\pm \mathrm{SD}$. The released CAF was detected by UV-vis spectrophotometry at $\lambda=273 \mathrm{~nm}$.

\section{Results and discussion}

The intercalation chemistry of $\mathrm{ZrP}$ is characterized by the presence of Brønsted acid groups in the interlayer region; the reaction is thus often driven by a topotactic acid-base reaction ${ }^{34}$ between the host and the guest. CAF is a weak base with a $\mathrm{p} K_{\mathrm{b}}$ of 10.4 , while protons in the phosphates of $\mathrm{ZrP}$ are a medium strong Brønsted acid. ${ }^{21}$ In order to intercalate CAF in

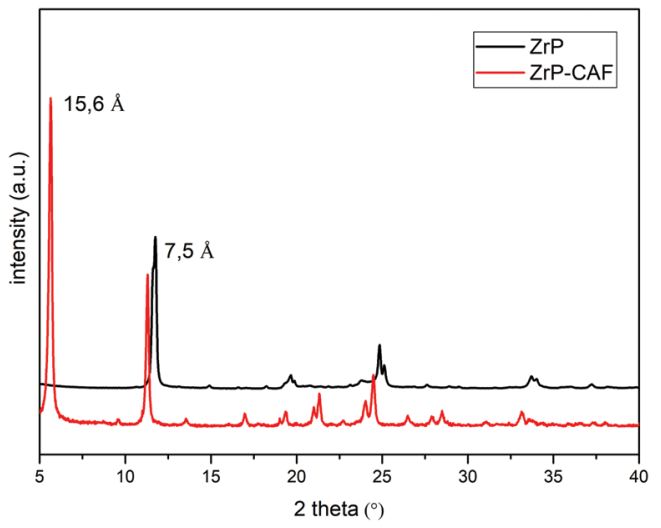

Fig. 3 XRPD patterns of ZrP (black) and ZrP-CAF intercalation compounds (red).

the chosen lamellar solid, a ZrP gel in water was used: in the ZrP gel protons are solvated by water and more accessible than in the solid form. ${ }^{35}$ The gel was obtained regenerating the acid form by adding $\mathrm{HCl}$ to a colloidal dispersion of $\mathrm{ZrP}-\mathrm{PrNH}_{2}$ in water, according to the work of Casciola et $a .^{36}$ Then a water solution of CAF was added to the gel, stirred $24 \mathrm{~h}$ and recovered by centrifugation. The product was dried in an oven to obtain a fine micropowder and characterized by XRPD, FT-IR, TGA, and DSC. The chemical-physical characterization clearly demonstrated that CAF was successfully intercalated into ZrP. The results of the XRPD analysis are reported in Fig. 3. The ZrP-CAF diffraction pattern is compared with that of the pristine $\mathrm{ZrP}$, which possesses an interlayer distance of $7.5 \AA$ typical of the acidic form. ${ }^{37}$ In $\mathrm{ZrP}-\mathrm{CAF}$ a reflection corresponding to $15.6 \AA$ is detectable, compatible with the intercalation of caffeine, when compared with the interlayer distances obtained for the intercalation of aromatic and heterocyclic bases. ${ }^{38}$ The increment from the starting interlayer distance is consistent with the presence of a monolayer of molecules lying perpendicular, or nearly perpendicular, to the layers of the host structure, ${ }^{39}$ considering the total interlayer distance of $15.6 \AA$, the caffeine dimension of $7.8 \AA \times 6.1 \AA \times 2.1 \AA^{40}$ and the layer thickness ${ }^{39}$ of about $7.6 \AA$ (see Fig. 4). The intercalation reaction was

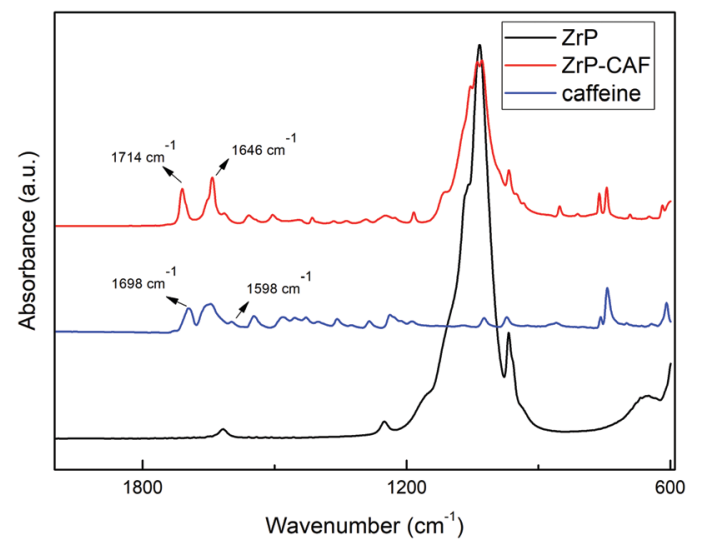

Fig. 4 FT-IR spectra of ZrP (black), ZrP-CAF intercalation compound (red), and CAF (blue). 


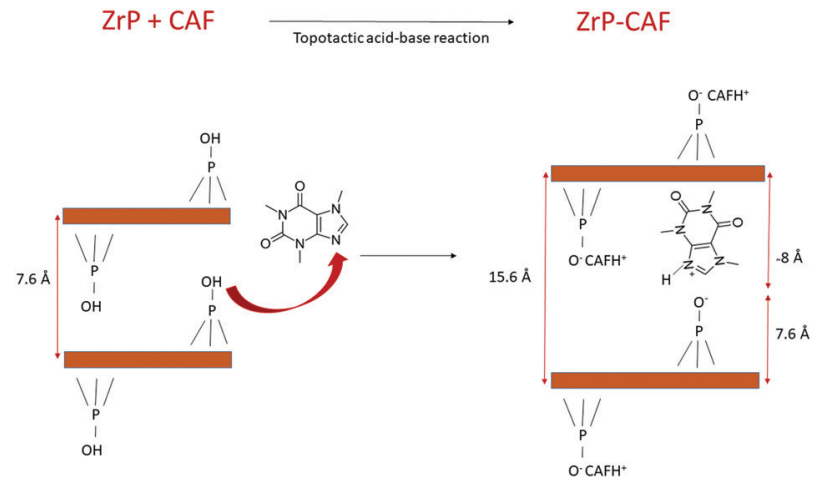

Fig. 5 Intercalation mechanism of CAF in ZrP.

effectively driven by an acid-base mechanism, as demonstrated by the FT-IR analysis.

In Fig. 4 the FT-IR spectra of ZrP, CAF and ZrP-CAF are reported. The typical signal detectable in a $\mathrm{ZrP}$ spectrum is the $\mathrm{P}=\mathrm{O}$ stretching at $\sim 1040 \mathrm{~cm}^{-1}$, that is still evident in the ZrP-CAF spectrum. ${ }^{19}$ The spectrum of pure caffeine is characterized by a region between 1750 and $1400 \mathrm{~cm}^{-1}$ that presents the signals generated by $\mathrm{C}=\mathrm{O}, \mathrm{C}=\mathrm{N}$, and $\mathrm{C}=\mathrm{C}$ bond vibrations. In detail, the signals generated by the two carboxylates in the anhydrous caffeine as free base can be detected at 1698 and $1656 \mathrm{~cm}^{-1}$. In the salt, the protonation leads to a shift of that signals towards higher frequencies, 1714 and $1675 \mathrm{~cm}^{-1}$ respectively, as observed in the ZrP-CAF spectrum. ${ }^{41}$ Also the shift from 1598 to $1646 \mathrm{~cm}^{-1}$ demonstrates that the free base is protonated, confirming the intercalation of the molecule in the interlayer region of zirconium phosphate through an acid-base reaction.

The intercalation mechanism is better explained in the scheme reported in Fig. 5. Herein a simple representation of the reaction is reported: the basic sites of CAF react with the acidic protons of ZrP generating the intercalation compound. For the sake of simplicity, the layers composed of $\mathrm{Zr}$ atoms are represented by brown lines, and only one molecule of caffeine has been completely reported.

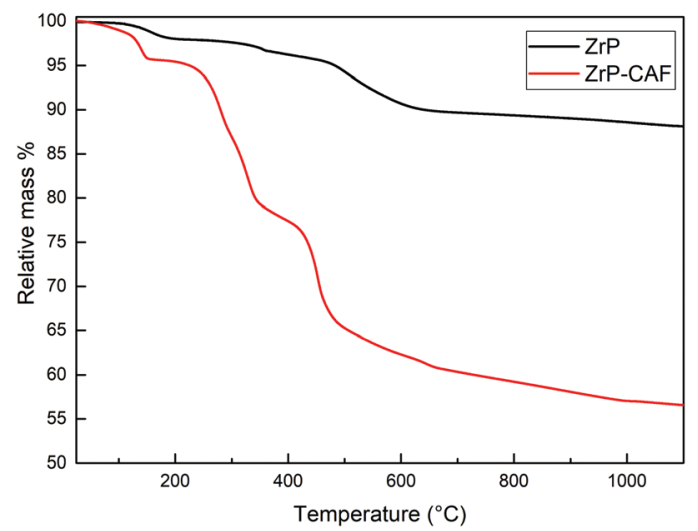

Fig. 6 TGA curves of ZrP (black) and ZrP-CAF intercalation compound (red).

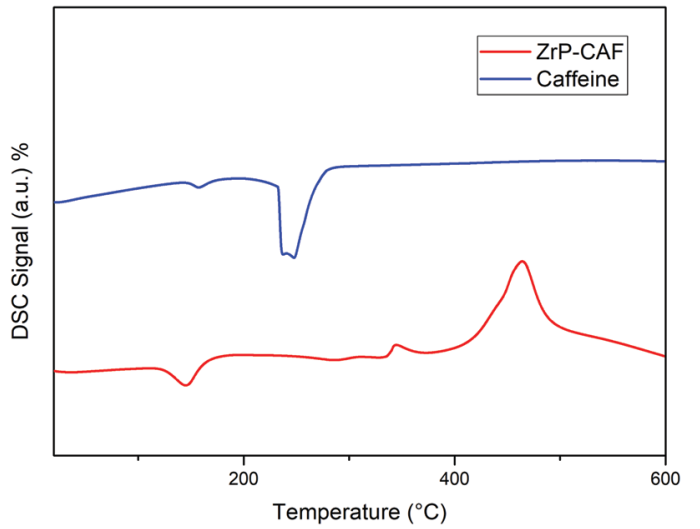

Fig. 7 DSC curves of caffeine (blue) and ZrP-CAF intercalation compound (red).

The position of the molecule has been chosen in order to represent the hypothesized perpendicular orientation, and the interlayer distances are reported. The caffeine loading into $\mathrm{ZrP}$ has been determined by TGA analysis. TGA curves of ZrP-CAF and pristine $\mathrm{ZrP}$ are reported in Fig. 6. ZrP shows two main weight losses: the loss of hydration water occurred in the range of $20-200{ }^{\circ} \mathrm{C}$, while the step between 200 and $800{ }^{\circ} \mathrm{C}$ is attributed to the loss of water due to the condensation of the $\mathrm{HPO}_{4}$ groups. The thermogravimetric curve of ZrP-CAF sample shows one main step in the range of $20-200{ }^{\circ} \mathrm{C}$ and two main steps between 200 and $800{ }^{\circ} \mathrm{C}$ : the first is due to the loss of water, while the other two can be attributed to the thermal decomposition of CAF and the condensation of the phosphate groups to produce zirconium pyrophosphate. The overall weight loss of the ZrP-CAF sample (red) is obviously higher when compared to the pristine $\mathrm{ZrP}$ material (black), because of the combustion of the organic part. From the difference in the weight loss it was possible to calculate the CAF content. The experimental caffeine content in the ZrP-CAF intercalation compound was about $31.8 \mathrm{wt} \%$ corresponding to the following chemical formula: $\mathrm{Zr}\left(\mathrm{HPO}_{4}\right)_{1.27}\left(\mathrm{PO}_{4}\right)_{0.73}(\mathrm{CAFH})_{0.73} \cdot 1.3 \mathrm{H}_{2} \mathrm{O}$. In order to confirm the amount of drug in the solid, CAF was extracted as described in the experimental part, by titrating the solid with sodium hydroxide:

$$
\begin{gathered}
\mathrm{Zr}\left(\mathrm{HPO}_{4}\right)_{1.27}\left(\mathrm{PO}_{4}\right)_{0.73}(\mathrm{CAFH})_{0.73}+2 \mathrm{NaOH} \rightarrow \mathrm{Na}_{2} \mathrm{Zr}\left(\mathrm{PO}_{4}\right)_{2}+ \\
0.73 \mathrm{CAF}+2 \mathrm{H}_{2} \mathrm{O}
\end{gathered}
$$

The extracted solution was analyzed by UV-vis spectroscopy and the result obtained confirmed the herein previously reported formula.

DSC analysis was carried out on pure caffeine and Zr-CAF intercalation compound samples. The DSC curve of pure caffeine (line blue, Fig. 7) exhibited an endothermic peak at $240{ }^{\circ} \mathrm{C}$ which corresponds to the crystalline CAF melting point. ${ }^{42}$ The DSC thermogram of the ZrP-CAF sample (line red) showed an endothermic peak at $145{ }^{\circ} \mathrm{C}$ due to the loss of crystallization water and two exothermic peaks due to the combustion of the organic part. In this DSC curve the lack of the CAF endothermic peak at $240{ }^{\circ} \mathrm{C}$ is a proof of the formation of a new compound 


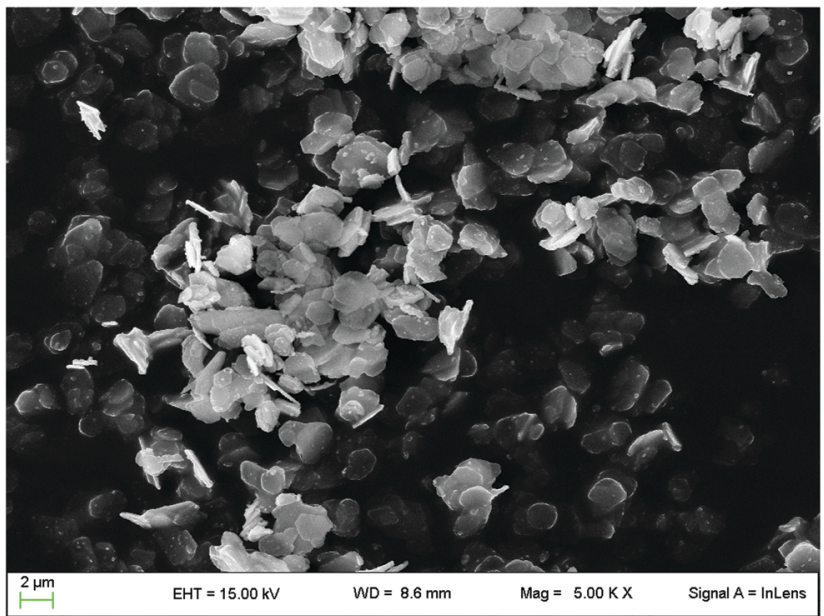

Fig. 8 SEM micrograph of the ZrP-CAF intercalation compound.

as a consequence of the drug intercalation into ZrP. These results suggest that the caffeine is intercalated in the interlayer region of zirconium phosphate in a molecular level of incorporation, that is classically observed when drugs are vehiculated in clays. ${ }^{43}$ After the intercalation, CAF does not retain its crystalline structure, having a new chemical-physical behaviour as demonstrated later by the release studies.

The SEM micrograph of the intercalation compound is reported in Fig. 8. Zirconium phosphate shows the typical lamellar structure, with pseudo-hexagonal shaped crystals of micrometric dimensions, as expected from the synthesis method that has been chosen. As expected, no crystals of caffeine were detected in the sample.

As discussed in the introduction, among the multiple biological activities of caffeine, the aim of this study is to test a topical application. The release method chosen for this study followed OECD guidelines for skin absorption, that uses a Franz-Cell, a well-known system for rapid and accurate investigation of drug diffusion. ${ }^{29}$ The skin permeability was simulated using the Strat-M membrane, a synthetic, non-animal based model for transdermal diffusion testing that is predictive of diffusion in human skin without lot-to-lot variability, safety or storage limitations. ${ }^{33}$ The emulsions containing pure caffeine and ZrP-CAF were carefully prepared as described in the experimental part, and used for the tests. $200 \mathrm{mg}$ of cream, corresponding to $8 \mathrm{mg}$ of caffeine, were used for the test. The amount of CAF released at each time was detected by UV-vis spectrophotometry at the wavelength of maximum absorption of caffeine in the phosphate buffer $(\lambda=273 \mathrm{~nm})$. All experiments showed a good reproducibility; the permeation profiles are reported in Fig. 9. The results are expressed in $\mu \mathrm{g} \mathrm{mL} \mathrm{m}^{-1}$ of permeated caffeine in the acceptor chamber. The caffeine permeation from the cream containing free caffeine is, as expected, a slow permeation that can be correlated to a hydrophilic drug, with a $\log P-0.07 .{ }^{10}$ Similar results were obtained by Farner $e t$ al., for the permeation of the pure caffeine from a cream at $4 \%,{ }^{44}$ using a Sartorius-cellulose acetate membrane.

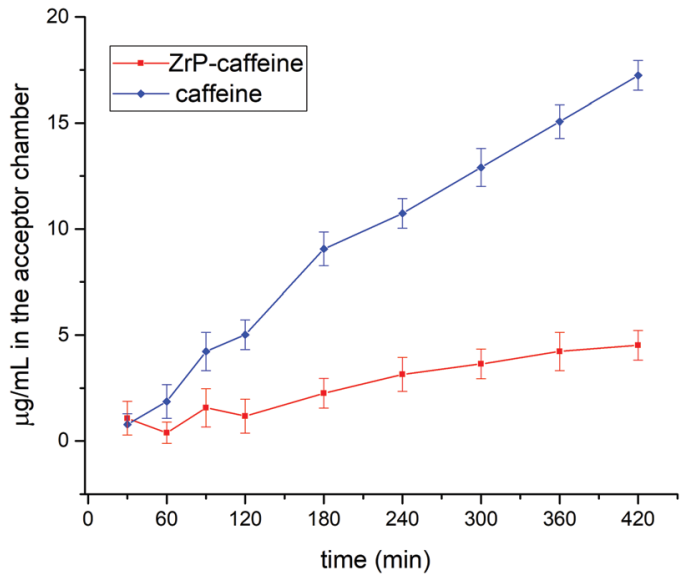

Fig. 9 Permeation profile from pure CAF (blue) and from ZrP-CAF (red), $\mu \mathrm{g} \mathrm{mL}{ }^{-1}$ vs. time.

The ZrP-CAF sample showed a slower permeation during the whole analyzed time range when compared to the pure caffeine.

The observed behavior can be attributed to the release mechanism expected from an intercalation compound: while pure CAF is ready for the permeation, in the intercalation compound the release is subsequent to a cationic exchange. Probably, the CAF release from the intercalation compound is due to $\mathrm{Na}^{+}$and $\mathrm{K}^{+}$cations that are able to permeate the membrane, reaching the cream, and activate the ion exchange in the ZrP-CAF. In fact, only after this exchange the caffeine can be ready to permeate the membrane. In order to validate this hypothesis XRD measurements were performed on the ZrP-CAF cream, and on the same cream after the permeation test. The analysis, reported in Fig. 10, shows that in the cream containing the ZrP-CAF the structure of the intercalation compound has been perfectly retained, while after the release test a new phase with an interlayer distance of $9.7 \AA$ is present, probably due to the intercalation of $\mathrm{Na}^{+}$and $\mathrm{K}^{+}$.

Thanks to the intercalation technology, the caffeine hosted in the interlayer region of $\mathrm{ZrP}$ can have a really slow release. ZrP-CAF possesses great potential in order to project slow release systems of caffeine, not only in cosmetics but also in

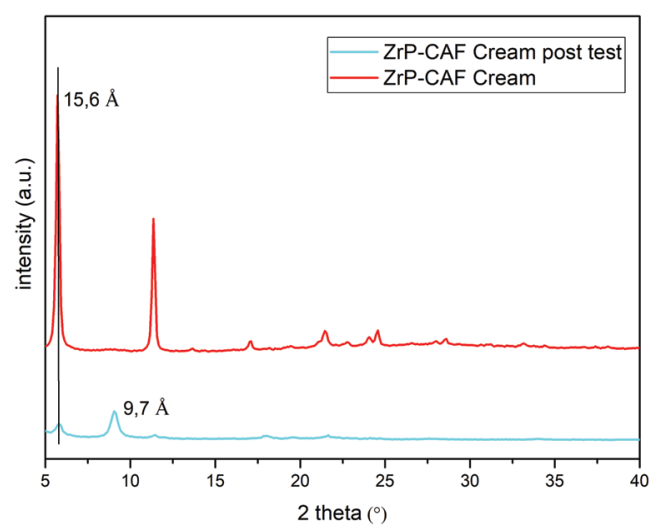

Fig. 10 XRD patterns of the ZrP-CAF cream (red) and ZrP-CAF cream after the permeation test (light blue). 
other fields of application. Moreover, the intercalation strategy described in this study could be an helpful tool to avoid the well-known crystallization problems of caffeine. Zirconium phosphate, as a drug delivery system for topical application, could be really promising for developing slow release system, like transdermal patches that require long time of delivery (weeks or months).

\section{Conclusions}

Caffeine is a well-known drug and zirconium phosphate is a lamellar solid able to host basic molecules. In this article the first intercalation of caffeine into zirconium phosphate is reported. The designed intercalation strategy was successful, as demonstrated by XRPD, FT-IR, TGA, and DSC analyses. The intercalation compound has been tested for topical release study after being formulated in an emulsion. The results obtained using the Franz Cell diffusion system showed that the intercalation confers to the drug a slower release if compared to the pure active.

\section{Conflicts of interest}

There are no conflicts to declare.

\section{Notes and references}

1 B. T. Gebeyehu and S. L. Bikila, Am. J. Appl. Chem., 2015, 3, 69-76.

2 A. Nehlig, J.-L. Daval and G. Debry, Brain Res. Rev., 1992, 17, 139-170.

3 B. Schmidt, Neonatology, 2005, 88, 208-213.

4 A. Cano-Marquina, J. J. Tarín and A. Cano, Maturitas, 2013, 75, 7-21.

5 H. Qi and S. Li, Geriatr. Gerontol. Int., 2014, 14, 430-439.

6 Z. Wang, C. Gu, X. Wang, Y. Lang, Y. Wu, X. Wu, X. Zhu, K. Wang and H. Yang, Med. Oncol., 2019, 36, 97.

7 Y.-F. Li, S.-H. Ouyang, L.-F. Tu, X. Wang, W.-L. Yuan, G.-E. Wang, Y.-P. Wu, W.-J. Duan, H.-M. Yu and Z.-Z. Fang, Theranostics, 2018, 8, 5713.

8 A. Herman and A. P. Herman, Skin Pharmacol. Physiol., 2013, 26, 8-14.

9 S. Koo, S. Hirakawa, S. Fujii, M. Kawasumi and P. Nghiem, Br. J. Dermatol., 2007, 156, 957-964.

10 L. Luo and M. E. Lane, Int. J. Pharm., 2015, 490, 155-164.

11 H. W. Kwak, H. Woo, I.-C. Kim and K. H. Lee, RSC Adv., 2017, 7, 40411-40417.

12 A. Clearfield and J. A. Stynes, J. Inorg. Nucl. Chem., 1964, 26, 117-129.

13 M. Pica, A. Donnadio and M. Casciola, Coord. Chem. Rev., 2018, 374, 218-235.

14 A. J. Jacobson and L. F. Nazar, Intercalation Chemistry, Encycl. Inorg. Bioinorg. Chem., 2011, DOI: 10.1002/9781119951438. eibc0093.
15 V. Saxena, A. Diaz, A. Clearfield, J. D. Batteas and M. D. Hussain, Nanoscale, 2013, 5, 2328-2336.

16 A. Díaz, M. L. González, R. J. Pérez, A. David, A. Mukherjee, A. Báez, A. Clearfield and J. L. Colón, Nanoscale, 2013, 5, 11456-11463.

17 J. González-Villegas, Y. Kan, V. I. Bakhmutov, A. GarcíaVargas, M. Martínez, A. Clearfield and J. L. Colón, Inorg. Chim. Acta, 2017, 468, 270-279.

18 R. Li, T. Liu and K. Wang, Biomed. Eng. Technol., 2017, 62, 67-73.

19 H. Ueoka, O. Shimomura, M. Pica, A. Donnadio and R. Nomura, Colloid Interface Sci. Commun., 2019, 28, 29-33.

20 M. Bastianini, M. Scatto, M. Sisani, P. Scopece, A. Patelli and A. Petracci, J. Compos. Sci., 2018, 2, 31.

21 A. Clearfield and G. D. Smith, Inorg. Chem., 1969, 8, 431-436.

22 T. Okada, J. Oguchi, K. Yamamoto, T. Shiono, M. Fujita and T. Iiyama, Langmuir, 2015, 31, 180-187.

23 K. Yamamoto, T. Shiono, Y. Matsui and M. Yoneda, Int. J. Geomate, 2016, 11, 2301-2306.

24 K. Yamamoto, T. Shiono, R. Yoshimura, Y. Matsui and M. Yoneda, Adsorpt. Sci. Technol., 2018, 36, 967-981.

25 T. Okada, T. Yoshida and T. Iiyama, J. Phys. Chem. B, 2017, 121, 6919-6925.

26 L. Marçal, E. H. de Faria, E. J. Nassar, R. Trujillano, N. Martín, M. A. Vicente, V. Rives, A. Gil, S. A. Korili and K. J. Ciuffi, ACS Appl. Mater. Interfaces, 2015, 7, 10853-10862.

27 W. A. Cabrera-Lafaurie, F. R. Román and A. J. HernándezMaldonado, J. Colloid Interface Sci., 2012, 386, 381-391.

28 K. Yamamoto, T. Shiono, Y. Matsui and M. Yoneda, Part. Sci. Technol., 2019, 37, 325-332.

29 OECD: OECD (2004), Test No. 428: Skin Absorption: In Vitro Method, OECD Guidelines for the Testing of Chemicals, Section 4, OECD Publishing.

30 A. Clearfield, W. L. Duax, A. S. Medina, G. D. Smith and J. R. Thomas, J. Phys. Chem., 1969, 73, 3424-3430.

31 U. Pharmacopeia, US Pharmacop. 32 NF27, 2009, 861-862.

32 A. Haq, M. Dorrani, B. Goodyear, V. Joshi and B. MichniakKohn, Int. J. Pharm., 2018, 539, 58-64.

33 T. Uchida, W. R. Kadhum, S. Kanai, H. Todo, T. Oshizaka and K. Sugibayashi, Eur. J. Pharm. Sci., 2015, 67, 113-118.

34 H. Xiao and S. Liu, Mater. Des., 2018, 155, 19-35.

35 U. Costantino, J. Chem. Soc., Dalton Trans., 1979, 402-405.

36 M. Casciola, G. Alberti, A. Donnadio, M. Pica, F. Marmottini, A. Bottino and P. Piaggio, J. Mater. Chem., 2005, 15, 4262-4267.

37 J. Albertsson, A. Oskarsson, R. Tellgren and J. O. Thomas, J. Phys. Chem., 1977, 81, 1574-1578.

38 Comprehensive Supramolecular Chemistry, ed. G. Alberti and T. Bein, vol. 7, 1996.

39 U. Costantino, M. A. Massucci, A. La Ginestra, A. M. Tarola and L. Zampa, J. Incl. Phenom., 1986, 4, 147-162.

40 V. I. Poltev, T. I. Grokhlina, E. González, A. Deriabina, A. Cruz, L. Gorb, J. Leszczynski, L. N. Djimant and A. N. Veselkov, THEOCHEM, 2004, 709, 123-128. 
41 D. Cook and Z. R. Regnier, Can. J. Chem., 1967, 45, 43 J.-H. Yang, J.-H. Lee, H.-J. Ryu, A. A. Elzatahry, Z. A. Alothman 2895-2897. and J.-H. Choy, Appl. Clay Sci., 2016, 130, 20-32.

42 S. S. Pinto and H. P. Diogo, J. Chem. Thermodyn., 2006, 38, 44 F. Farner, L. Bors, Á. Bajza, G. Karvaly, I. Antal and F. Erdö, 1515-1522. Drug Delivery Lett., 2018, 9, 15-20. 